\title{
Adolescent Girls' Vulnerability to HIV Infection in Dar es Salaam: The Need to Link Protection with Prevention Beyond Behaviour Change
}

\author{
Richard Mabala
}

\begin{abstract}
1 Introduction and conceptual framework
This article draws upon a comparative survey of young people's vulnerability to HIV and primary research conducted in two wards of Dar es Salaam, Tanzania, by two Tanzanian organisations, Tamasha and Tanzania Development Research Group (TADREG), into the social and economic sources of vulnerability to HIV infection of adolescent girls and young women. Two wards were chosen, Magomeni and Azimio, and in each ward, three neighbourhoods were selected: one relatively better off, one relatively worse off and one average. In each neighbourhood, after a participatory mapping, 200 households were given a household questionnaire, resulting in a household sample of 1,200. After the survey, focus group discussions were held with groups of 10-20 girls and young women aged 12-24 in each neighbourhood, and one further discussion was held with girls who had migrated into those neighbourhoods. Overall, more than 100 girls participated in these discussions, which were conducted by young researchers who were the peers of their subjects.
\end{abstract}

At its simplest, vulnerability can be defined as a likelihood of being harmed. In the case of vulnerability to HIV infection, this relates to the chances that an individual will be put - or put her/himself - in a dangerous situation (e.g. unprotected sexual intercourse, or intravenous drug use with shared or unclean injecting equipment), that this exposes her/him directly to the virus, and the risk that this hazardous contact will lead to HIV transmission (a product of biological and epidemiological factors). In addition, if a person becomes infected, there is a high likelihood that she/he will encounter further harm in several ways (physically, economically, socially, emotionally etc.), which is often thought of as vulnerability to the impacts of HIV or AIDS. This article focuses mainly on vulnerability to becoming infected.

Vulnerability is also often more broadly defined in terms of risk of social and economic adversity such as unemployment, homelessness, physical abuse, or impoverishment, which may stem from various sources of misfortune - including from HIV infection or, becoming affected by the impacts of AIDS-related mortality or morbidity. There is an overlap between these two uses of the term vulnerability - to contracting HIV and to socioeconomic distress and deprivation of rights, which can in turn lead to risks of contracting HIV. Girls' vulnerability is a combination of: higher biological susceptibility at younger ages, lack of individual decision-making power, sociocultural and economic gendered disadvantages that precipitate risk, as well as the extent to which existing policies and programmes do or do not protect adolescent girls and young women. These vulnerabilities and lack of protection are major contributors to the risks of contracting HIV.

However, it would be an error to assume that the two kinds of vulnerabilities always coincide or that one entirely explains the other. For example, we 
might assume that the risk of contracting HIV for a young migrant woman who has fled rural poverty and become a commercial sex worker in the capital city is significantly higher than the probability that a city-born secondary schoolgirl from a non-poor household becomes infected. But this assumption may be wrong in individual cases. The better-off schoolgirl may be exposed to infection by being an unwitting member of a complex sexual network involving her sexual partner or partners. One of the major findings from the study in Dar es Salaam was that almost all adolescents face a risk of HIV.

\section{Why pay attention to adolescent girls ${ }^{1}$}

Being young and female in parts of Africa seems to be a major risk factor

(Otoo-Oyortey and Pobi 2003)

In sub-Saharan Africa and other parts of the developing world, HIV/AIDS is highly gender and age specific. Data overwhelmingly indicate the relative risks of HIV infection among young women in comparison to young men. For more than a decade, UNAIDS surveillance data have indicated not only the growing feminisation of the epidemic but also the extremely sharp gender disparity in infection rates among adolescents. Thus, young women and girls aged 15-24 - those who have only recently become sexually active - are 2.5 times more likely to be infected than males of the same age. The gap is larger still in southern Africa, where in Zambia and Zimbabwe girls and young women make up close to 80 per cent of all young people aged 15-24 who are living with HIV/AIDS (UNAIDS 2004).

The article by Stuart Gillespie in this IDS Bulletin reviews evidence for the association between poverty and the risks of HIV infection. Gillespie notes that Demographic and Health Surveys (DHSs) show that women in the highest educational and economic quintile have higher rates of HIV prevalence than those in the lowest quintile. However, he also points out several complicating factors, notably that gender and socioeconomic inequalities are closely associated with HIV risks, and that in particular circumstances, poverty is a factor in vulnerability to HIV. Among these latter circumstances is the increased vulnerability of poor young women to infection by older and more affluent men. Data from the Tanzania Health Indicator Survey (THIS) confirm this (Kaimu et al. 2005). ${ }^{2}$ This adds weight to the arguments by
Barnett and Whiteside (2002) and Stillwaggon (2006), that it is inequity, rather than poverty which drives the epidemic.

The policy and programming debates around HIV prevention have tended to focus on a simplified either/or - either HIV is driven by poverty (and therefore poverty reduction policies are the answer), or it is individual behaviours such as early sexual debut and multiple partners (and therefore the ' $A B C$ ' approach to behaviour change is the answer). What neither of these approaches grasp is that there is a specific crisis among a clearly identifiable population subgroup, namely adolescents and young women, for whom socioeconomic vulnerabilities are an important (though not a sole) determinant of HIV vulnerability, and for whom behaviour change interventions have limited relevance. Adolescent girls and young women have long been stigmatised as 'badly behaved' and, since the outbreak of the HIV/AIDS epidemic, young women and especially sex workers have often been labelled as the 'carriers' or 'core transmitter groups' responsible for infections in the population in general. Behavioural change efforts have had little impact on their HIV vulnerability, because they know how to prevent HIV infection but do not have the power to alter the circumstances in which they are at risk. The UN Secretary General's working group on women and HIV in Southern Africa (UNAIDS 2004) concluded that for most girls in the region, $\mathrm{ABC}$ is not an option

Poverty reduction strategies have neglected adolescent girls and women in favour of economic growth policies aimed at macroeconomic performance and social protection policies that favour mature families. Indicative of this is a survey of 55 Poverty Reduction Strategy Papers (PRSPs) which found that young people are under-represented, despite their large share of the populations of poor countries. Only one in five PRSPs identify young people as a major group vulnerable to poverty. Another one in three PRSPs identify in a minor way young people's vulnerability to poverty. One in four PRSPs identify youth as merely one of several groups vulnerable to poverty. In addition, while seven out of ten PRSPs mention young people in their action plans, only four out of ten address youth issues as a key goal and even where young people are a focus in the PRSP action plans, there is little follow-through in terms of specific targets or budgetary allocations for implementation (UNFPA n.d.). There is now a risk 
that the debunking of the 'poverty drives HIV/AIDS view will lead to a neglect of all socioeconomic factors that are associated with vulnerability to HIV. For these reasons, it is important that the specific circumstances in which adolescent girls and young women find themselves are brought clearly into focus.

\section{Dimensions of vulnerability}

The Dar es Salaam research study mapped out the dimensions of vulnerability for adolescent girls and young women. The single most compelling finding from the study was that adolescent girls are not safe anywhere in the city. As soon as a girl reaches puberty, she is considered to be a sexual human being. Thus, from the age of about 12, girls are subjected to continual propositioning from shopkeepers and market-stall holders, teachers and doctors, bus conductors and passers-by. One of the young researchers estimated that she was propositioned 10-30 times a day. This is not to say that every individual case of propositioning is unwelcome to the girls, but the non-stop nature of the propositioning, which continues even if the girl shows no interest, accompanied by threats if the propositioner perceives that he is not being given the 'respect' he deserves, constitutes sexual harassment, for which the girls have not been prepared. There is also strong peer pressure to have sex.

Largely as a result of the above, many girls in Dar es Salaam become sexually active at a very early age, often for pecuniary rather than hormonal reasons, in some cases even before puberty. They start in primary school, or 'if they are very determined to delay', just after leaving primary school. Most of these sexual encounters occur with little or no protection, with the result that many girls also get pregnant at an early age which then seriously affects their lives, whether they decide to give birth, or to have an abortion (which is illegal, with attendant health risks). Many young mothers end up as sex workers.

There is a thin dividing line also between sexual harassment and abuse, between blandishments and threats. In Dar es Salaam, respondents stated over and over again that if the girls are perceived to be too assertive in their refusals, or even if they just refuse, then they are threatened with rape or even gang rape. Thus, the girls need to have a 'protector' who is their boyfriend but who also expects sexual favours in return for protecting the girl from other men.
Thus, it is not surprising that sexual abuse figures highly in the lives of young girls. This abuse constitutes an epidemic in its own right in the broader region. ${ }^{3}$ For example a study in Uganda found that 49 per cent of sexually active primary school girls said they had been forced to have sexual intercourse (Noble et al. 1996). Sexual abuse is particularly prevalent in urban areas. In South Africa, poor urban girls aged 14-19 are much more likely than same age poor rural girls to report their first sexual experience as non-consensual (56 vs. 37 per cent) (Hallman 2004). As a result, in South Africa it is estimated that below age 15, child sexual abuse is replacing mother-to-child transmission as the major reason for HIV prevalence. $A$ recent study shows that rape increases the likelihood of HIV infection by 30 per cent, quite apart from all the other physical and psychological problems (CADRE 2004). In other studies, a large percentage of adolescent girls report forced sexual initiation.

Given the fact that education is regarded as an important preventative factor for girls, it is ironic that schools are also places of sexual abuse. The girls in the Dar es Salaam study gave many examples of sexual abuse and/or harassment within the school setting, including girls who were punished for a month for refusing the advances of a teacher. Many girls then drop out of school because of their fear or their parents' fear - of harassment. This issue also broadens within in the region. For example, in South Africa, Human Rights Watch (2002: 21) was told by girls of an environment where, 'violent, harassing and degrading sexual assaults are so normalised in many schools that they constituted a systemic problem for education, not merely a series of incidents'. Similarly, in Zambia, Human Rights Watch reports that 'even school environments are not always safe with sexual abuse or exploitation all too frequent. Teachers ${ }^{4}$ themselves may prey on vulnerable girls... Most abuses are not reported and few teachers are penalized'.

According to the researchers in Dar es Salaam, young respondents did not regard sex with underage girls as sexual abuse, provided that the girls accepted gifts, however small. Some of them argued that coerced sex was only rape if more than one man was involved. The ever-present threat of rape puts girls in a Catch 22 situation. In order to protect themselves from other men, they have to have a boyfriend. However, that boyfriend will also expect sexual 
favours, probably with even less chance of using a condom. The chances of being protected by the law are small.

Human Rights Watch (2002: 23) notes that 'A central problem in many African countries is the failure of the state and particularly the criminal justice system to deal appropriately with complaints of sexual abuse' and itemises many barriers to effective reporting and abuse. Quite apart from the distance to a police post or health institution, reporting means facing a police or health service provider who assumes she was promiscuous; a court system lacking any facilities for adolescents; and official inaction as well as a social structure that teaches girls to be submissive - this exacerbates a situation where there is already reluctance to follow up on abuse. The report continues, 'Official inaction on the part of the criminal justice system helps to perpetuate the abuse by contributing to a climate in which girls who suffer sexual violence decide it is not worth reporting abuse or rape to the police because of the unlikelihood of punishment of perpetrators and by sending a message to the perpetrators that they can commit abuse with impunity. As a result the perpetrators remain free to abuse again' (Human Rights Watch 2002: 23).

In a patriarchal system which protects men, it is hard to overcome the factors which allow for impunity for the perpetrators of sexual abuse. Prominent among these is the victim's dependence on the abuser, who may be father, step-father or caretaker, or a man such as an employer, landlord or patron on whom the family depends economically. Families hide the abuse, because of shame, or because they are paid some compensation by the abuser. Girls remain silent because of fear or lack of faith in the system and do not want to expose themselves for no perceived benefit.

Both marriage and sexual liaisons for young adolescents (or child prostitution) are often pursued as parts of livelihood strategies by poor households (if not always recognised as prostitution). In the Dar es Salaam study, it was found that girls as young as 12 were expected to contribute to the family income, otherwise they would not be allowed to eat. Similarly, when girls are viewed as an additional burden on family resources, they tend to be married off earlier as a family survival strategy (Otoo-Oyortey and Pobi 2003). During a famine in Malawi, it was observed that the age of marriage was reduced to as low as 12 (Semu-Banda 2003).

Within a context that limits their agency, girls try to obtain the least bad deal. Many become active 'players' during their adolescence. In the Dar es Salaam study, they stated candidly that they prefer older men because they are less sexually demanding, give them money and enable them to access food, education and material goods. For example, many girls were able to return to school and complete secondary education because of having such liaisons. However, the findings show clearly that the girls discount their disadvantages and focus only on their possibilities for reward. They enter the arena of negotiating transactional sex thinking that they are in control of the game, without realising that the cards are stacked against them. And indeed, given their inability to change the game, their best immediate options are often to trade sex for money and the (limited) protection afforded by a boyfriend. This biased perception is largely caused by the nature of education which the girls receive. Notably, behaviour change communication emphasises individual agency and the ability of the girls to freely choose.

The reality is that for the majority of girls the famous 'ABC' formula has little relevance. Yet, they have been so thoroughly inculcated with the ideology of personal responsibility for sexual behaviour that even if their fellow girls are raped or harassed, the girls blame them for 'desiring nice things', or 'dressing wrongly', or 'dancing too sexily'. Similarly, if they get pregnant or sick they can only expect blame and those who become infected with HIV blame themselves because they did not 'change their behaviour'. The behaviour change model has been successful, not only in shifting the blame to the victim but even convincing the victim to blame herself. It does not equip the girls to cope with the challenges of growing up.

In the Dar es Salaam study, pregnancy at an early age is a common issue and generally spells disaster for the girl. If she gets pregnant, the father usually runs away, denies that he is the father or - in the case of a boy - says that he is too young to become a father. Sometimes he offers money to the girl to have an abortion. If the girl is still a student, or the father refuses the baby, or she is faced with the prospect of an unwelcome marriage, she will usually have an abortion often in unhygienic conditions. $A$ high 
percentage of maternal morbidity and mortality is the result of unsafe backstreet abortions.

\section{Factors determining vulnerability}

Much has been made of the increased vulnerability of children to HIV as a result of the death of one or both parents from AIDS. The Dar es Salaam study found evidence in support of this. Of the adolescents working as sex workers, 75 per cent were orphans while the other 25 per cent came from homes where one of the parents was absent. This is consistent with findings from elsewhere, for example that orphans living in stressed households are likely to be mistreated, and abused by caregivers; deprived of their inheritances by opportunist relatives and neighbours; forced to drop out of school to perform domestic labour or bring home wages; pressured into entering commercial sex work and vulnerable to sexual abuse (Rajaraman 2001). The Population Council Research in Ethiopia and Kenya also found that orphaned girls are two-and-a-half times more likely to have ever traded sex for money goods or favours than non-orphaned girls (6 per cent vs. 15 per cent) (Hallman 2004)

Migration emerged as a major determinant of vulnerability in Dar es Salaam, as elsewhere (e.g. Addis Ababa, Erulkar et al. 2004). Tanzania's DHS survey shows that many adolescents migrate, that many young migrants are running away from conditions at home, and that more girls and boys migrate to the city. Such distressed migrants are vulnerable to exploitation, abuse and HIV infection. They move to the poorest parts of town, are less likely to be in school, are more likely to be in exploitative working conditions, and are far more likely to be subjected to forced sex in comparison with more socially connected girls (Hallman and Diere 2005).

Location of residence is important. It is welldocumented that HIV rates are higher in urban than rural areas. It is less often observed that there are differences within urban areas. Vulnerabilities are higher in the poorest urban neighbourhoods. For example, in a survey of 1,600 children and adolescents in four poor urban communities in Zambia's capital, Lusaka, over one-quarter of children aged ten said they had already had sex and the figure rose to 60 per cent among 14-year-olds (UNICEF 2002).

The need to travel within the city, especially using public transport, is a factor in vulnerability. Girls are vulnerable as soon as they enter a public space. $A$ particular issue is related to travel to and from school. Girls in Dar es Salaam saw transport as a factor in vulnerability. The poorer girls accepted propositions from bus drivers or conductors for financial reasons, whereas the girls from the betteroff neighbourhoods tended to go to schools that were further away, and were therefore very dependent on the bus conductors to get to school on time or get home before darkness (and risk a walk in the darkness to their home), which left them vulnerable. ${ }^{5}$ Similar findings are also reported from Zambia by Human Rights Watch (2002): 'The length of the girls' commute to school is an important factor since their risk of sexual abuse by minibus drivers or conductors, if they take transportation, or abuse by others along the road if they walk can be significant. The long distance to school ... makes some girls stay in insecure, unsafe structures nearer to school during the week, which then exposes them to abuses by men who can walk in at will'.

In Dar es Salaam, the walk to the market, or the shops, or visiting relatives all entail risks. Places of recreation, such as the beach or dances are also locations of risk, with the threat of sexual harassment and abuse, and the concomitant need to have a boyfriend as protector. In addition, girls commented that if one of them is raped at a dance it is 'her fault'.

Marriage is also a risk factor and particularly early marriage. Interestingly, early marriage is not confined to rural areas where traditions may be stronger, but is also found in cities such as Dar es Salaam. The reasons for early marriage include the parents' need for money and the girls' hope for an escape from poverty through marrying an older and better-off man. Many girls instead found themselves exploited and abused by their partner. Other studies in east Africa find that HIV prevalence among married young women is higher than among sexually active unmarried adolescents (Ajayi 2004). These findings cast doubt on the effectiveness of promoting marriage (and, implicitly, faithfulness) as a prevention strategy.

\section{Conclusions and implications}

The major lessons learned from the study in Dar es Salaam resonating with other research in the region is the magnitude and multiple causes of vulnerability facing adolescent girls in general. This arises from an intersection of relative poverty (or economic inequality), fragile livelihoods and gender inequity, 
within a context of social norms that enable men who engage in sexual harassment, exploitation and violence to act with impunity. Adolescent girls are simultaneously exploited and sexualised, treated as commodities and not given either the protection or the tools with which to withstand relentless pressures. Meanuhile, behaviour change messages serve chiefly to internalise girls' sense of personal responsibility for outcomes over which they have very little real control. Girls are given little-to-no relevant training to cope with this situation, apart from general messages to 'just say no' or 'wait until you are married'. Although the Ministry of Education claims that life skills have been integrated into the curriculum, ongoing discussions with stakeholders reveal that, except in specific interventions, the children do not perceive that they have been taught any life skills and many of the teachers concerned say that they have not been trained to teach them (Mabala 2008). Thus, the girls do not receive any meaningful life skills training in school, and there is no concerted effort to enable girls to think and discuss together how to confront such situations, and next-to-no support from adults or governmental authorities. Girls have so internalised this patriarchal

\section{Notes}

1 Much of the material for this section and some of the subsequent sections is drawn from R. Mabala, 'Youth Health', in African Youth Report (UNECA forthcoming).

2 THIS accepted that the correlation between increased wealth and HIV did not apply to young people.

\section{References}

Ajayi, A. (2004) 'Early Marriage and HIV Population Council', paper presented to a Workshop on Preventing HIV Infection in Girls and Young Women, Nairobi

Barnett, T. and Whiteside, A. (2002) AIDS in the Twenty First Century: Disease and Globalisation, Basingstoke: Palgrave Macmillan

CADRE (2004) Child Sexual Abuse, HIV and AIDS in South Africa: A Review, Johannesburg: Centre for AIDS Development, Research and Evaluation (CADRE)

Erulkar, A.; Mekbib, T.; Simie, N. and Gulema, T. (2004) Adolescent Life in Low-income and Slum Areas of system that they do not see that their rights are being violated and instead they blame themselves or one another for whatever personal disasters befall them. Meanwhile, men are protected by the same patriarchal system which endorses their behaviour, as boys become socialised into expecting that the one privilege they can count on is that of supremacy over - and access to - girls, as they grow up. It is not merely a question of lots of 'men behaving badly', but rather a system that validates and reproduces certain sorts of behaviour.

The prospects for changing this system, with its attendant threats to the rights, health, wellbeing and lives of girls and women (and its less obvious, but real, threats to boys and men), do not lie in interventions aimed at individual behaviour change. There is little prospect of success for such approaches, while individual girls, or boys, try to navigate the system with greater or lesser success, with little social or structural support. Rather, collective action that brings young people into partnership with other forces for change, national and international, raises the prospect of transforming social and economic structures.

3 The examples given come from www.advocatesforyouth.org/publications/ factsheet/fssxabus.htm (accessed 21 August 2005).

4 And other workers in school, and fellow students.

5 Because of very differential fares for students, the drivers and conductors of the small, private, commuter buses often refuse to take students on the bus.

Addis Ababa, Ethiopia, Addis Ababa: Population Council/Ministry of Youth Sports and Culture Hallman, K. (2004) Socioeconomic Disadvantage and Unsafe Sexual Behaviours of Young Women and Men in South Africa, Policy Research Division Working Paper 190, New York: Population Council

Hallman, K. and Diere, J. (2005) 'Social Isolation and Economic Vulnerability: Adolescent HIV and Pregnancy Risk Factors in South Africa', Poster presentation at the 2005 Annual Meeting of the Population Association of America, Boston, MA

Human Rights Watch (2002) Suffering in Silence: the Links between Human Rights Abuses and HIV 
Transmission to Girls in Zambia, New York: Human Rights Watch

Kaimu, A.M.; Aboud S.M.; Chuwa A. A.; Karugendo E.N. and Chonjo, J.P. (2005) Tanzania Health Indicator Survey (THIS), Dar es Salaam: Tanzania Commission for AIDS

Mabala, R. (2008) 'Stakeholders Report into Life Skills in Tanzania in Preparation for Development of National Life Skills Framework', Draft for Ministry of Education and Vocational Training

Noble J.; Cover J. and Yangishita, M. (1996) The World's Youth, Washington DC: Population Reference Bureau

Otoo-Oyortey, N. and Pobi, S. (2003) Early Marriage and Poverty: Exploring Links for Policy and Programme Development, London: International Planned Parenthood Federation (IPPF) and Forum on Marriage and the Rights of Women and Girls

Rajaraman, D. (2001) 'The Future of the Nation:

HIV/AIDS and Orphans in Botswana', unpublished paper
Semu-Banda, P. (2003) 'Daughters for Loan under Fire', The Nation Online 24: 'Girls Exchanged for Food', SAHIMS editorial, www.sahims.net/countries/ Malawi/editorial/review_mal_06_08_03.htm (accessed 5 July 2008)

Stillwaggon, E. (2006) Aids and the Ecology of Poverty, Oxford: Oxford University Press

UNAIDS (Joint United Nations Programme on HIV/ AIDS) (2004) Facing the Future Together, Report of the Secretary General's Task Force on Women, Girls and HIV/AIDS in Southern Africa, Geneva: UNAIDS

UNFPA (n.d.) 'Putting Young People into Poverty Reduction Strategies: A Guide to Statistics on Young People in Poverty', New York: UNFPA

UNICEF (2002) 'Adolescence: A Time that Matters', in Helen Jackson (ed.), AIDS Africa Continent in Crisis, Harare: SafAIDS 